\title{
CORRESPONDENCE
}

Correspondents are asked to be briet

Thyroid Scanning

K. E. Britton, M.D., M.SC., M.R.C.P., and P.

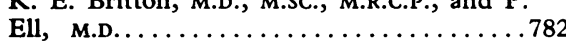

Coma and Convulsions Associated with Vincristine Therapy

J. Martin, M.R.C.P., and Dorothy Mainwaring,

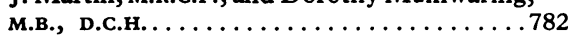

Pyrimethamine Poisoning

J. Armata, M.D...............783

Diathermy Burn Hazard

A. G. Nash, F.R.C.S............783

Drugs and Dementia in the Elderly

B. F. B. Russell, M.D. . . . . . . . . . . 783
Anaemia in the Elderly

J. H. Thomas, M.R.C.P...........783

Doctors in South Africa

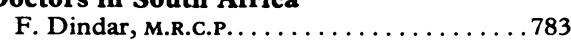

Making Hospital Geriatrics Work

P. P. Mayer, M.R.C.P. . . . . . . . . . 784

Home Graduates Only

K. Raghavan, M.B..............784

High Dose Frusemide in Established Acute Renal Failure

Y. K. Seedat, M.D. . . . . . . . . . . . .784

F.D.P. Levels in Intravascular Haemolysis

E. N. Wardle, M.R.C.P...........784
Analgesics and the Kidney

R. A. Axelsen, M.B., and A. F. Burry, M.D. . 784

Suppository Inserter: New Aid for the Disabled

A. T. Day, M.R.C.G.P...... . . . 785

Abortion in 1972

P. L. C. Diggory, F.R.C.s. . . . . . . . . . 785

Adoption Problems

M. Phillida, T. Sawbridge, B.A., and Wanda

McClanahan, M.S.w.(U.S.A.). . . . . . . 785

Seat Belt Syndrome

J. M. Shennan, F.R.C.s. . . . . . . . . 786

Think Again on Salmon

L. J. Temple, F.R.C.s. . . . . . . . . . 786

\section{Thyroid Scanning}

SIR,-The appearance, within a month, of a leading article on "The Solitary Thyroid Nodule" (10 November, p. 31) and a clear survey of the "Clinical Diagnosis of Thyroid Cancer" (Messrs. M. D. Staunton and W. P. Greening, 1 December, p. 532) calls for comment on their differing advice regarding the scanning of the thyroid. The first, having reviewed the incidence of cancer in solitary nodules, considers that "it should be possible to predict with some accuracy today what lesions ought to be removed surgically" and goes on to state that "the thyroid should be scanned, and if the nodule is solitary and 'cold' that is probably a firm indication that surgery is indicated" (our italics). The second quotes Werner's ${ }^{1}$ statement that "isotope scanning has achieved no high degree of predictability in the diagnosis of thyroid cancer." The hope and the fact are stated.

Will a thyroid scan diagnose a nodule to be solitary? Let us assume that the resoultion of a scanner or gamma camera is such that it will pick up "cold" areas in the thyroid down to $0.5 \mathrm{~cm}$ diameter. What effect does a nodule of $0.4 \mathrm{~cm}$, which may be palpable, have on this approach? Does or does not the presence of an undetected nodule $0.4 \mathrm{~cm}$ across invalidate the concept of the solitary nodule? Multiplicity of nodules does not exclude cancer. Surely if there is sufficient clinical suspicion of cancer to warrant requesting a scan, there is sufficient clinical suspicion to demand histological examination of that gland, whatever the scan shows.

In defence of the scan it may be argued that the discovery of a "cold" nodule $90 \%$ of the total according to Messrs. Staunton and Greening) will save an operation on a "hot" nodule. A truly "hot" nodule is autonomous and, if it is nor already causing hyperthyroid function (diagnosable by the relevant blood tests), it will probably grow to do so. Surgery here is the treatment of choice at least up to the age of 45 .

What then is the place of thyroid scanning? It is to be used when there is a mass outside the usual position of the thyroid that could be thyroid tissue-the retrosternal mass; the thyroglossal cyst that may contain the patient's only thyroid tissue; the lingual thyroid; the possibly functioning metastasis of a thyroid cancer. Let us use our best resolution and our techniques of computer analysis of scans for the case where at the patient's presentation there is in the neck "an enlarged node with no obvious mass in the thyroid gland."

Let us once and for all agree that the presence of a mass or masses in the thyroid is no longer the reason for scanning thyroid tissue. Let us be aware that the thyroid scan is in danger of being misused as a substitute for careful clinical palpation of the gland and its environment. Careful examination matters in the clinical diagonsis of thyroid cancer, and suspicion of cancer should lead directly to histological confirmation. Alternatively, shall we conclude that the thyroid scan (as are so many diagnostic tests) is

being used to prolong the time so necessary for the decision-making process, or as something extra for a visiting consultant to request as another patient-bed-day slips by?

It is now so easy to suggest and send a request to a diagnostic department that serious reflection on how the result is likely to affect the clinical management, the time off work of the patient, and the economics of the Health Service may be short-circuited. As evidence of lack of reflection, the filling up of a request form accurately and with relevant information has become a literary exercise involving such a high degree of concentration and manual labour that it appears to be beyond the ability of so many.-We are, etc.,

KeITH BRITTON PETER ELL

Institute of Nuclear Medicine,
Middlesex Hospital Medical School,

London W.1

Werner, S. C., in Thyroid, ed. S. C. Werner and erner, S. C., in Thyroid, ed. S. C. Werner and
S. Ingbar. New York, Harper and Row, 1971.

\section{Coma and Convulsions Associated with Vincristine Therapy}

SIR,-We read with interest the recent article (10 November, p. 335) by Dr. J. A. Whittaker and others describing three cases of reversible coma after vincristine therapy. During the past six years we have seen five children in whom otherwise unexplained coma and convulsions occurred during or shortly after their first course of treatment with vincristine. Four of these children were receiving therapy for acute lymphatic leukaemia and the fifth child for nephroblastoma. Their ages ranged from three to 11 years. In each child the episode of coma with numerous convulsions occurred 2-10 days after a vincristine injection. In two children it was after the second injection, in two after the third, and in one after the fourth weekly injection. The dose given was $1.5 \mathrm{mg} / \mathrm{m}^{2}$ in three cases and $2 \mathrm{mg} / \mathrm{m}^{2}$ in two. Examination of the cerebrospinal fluid showed no significant abnormality in four of the five cases, but the E.E.G. was very disorganized in the four cases in which it was recorded. Electrolyte estimations in three cases showed no changes suggestive of inappropriate secretion of antidiuretic hormone. The period of coma lasted from 24 hours to seven days and all the children recovered completely from the episode. One child was given further vincristine injections, restarting 11 days after the convulsive episode, and had no subsequent reaction.

If our experience is typical it would suggest that these neurological complications of vincristine are by no means as rare as the reports in the literature suggest. The incidence is difficult to estimate, but we treat approximately 25-30 new patients with vincristine each year and have seen this complication five times in six years. It is important to be aware of this possibility in patients receiving vincristine as otherwise 
more serious diagnoses may be made, carrying a less favourable prognosis.-We are, etc.

JOHN MARTIN

DOROTHY MAINWARING

Department of Child Health,
Alder Hey Children's Hospital,

Liverpool

\section{Pyrimethamine Poisoning}

SIR,-In their extremely interesting article (20 October, p. 147) Dr. Olu Akinyanju and his colleagues reported two cases of pyrimethamine poisoning in children, in one of which the manifestations included convulsions. Convulsions may also occur when pyrimethamine is given in therapeutic doses. ${ }^{1-3}$ Geils et al. ${ }^{1}$ have shown that pyrimethamine may be of valus in the treatmen of leukaemia of the central nervous system; others": have confirmed this but have shown that the drug is highly toxic.

Th:re are known to bs better and welltried methods for the prophylaxis and treat ment of C.N.S. leukaemias" and the use of pyrimethamine in this condition should therefore be limited to those cases in which other types of therapy are contraindicated or refused either by the patient or, in the case of a child, his par'nts. In our experience," in th: treatment of meningea leukatmia pyrimethamine should not be used directly after methotrexate and its daily dosage should not exceed $2-3 \mathrm{mg} / \mathrm{kg}$ body weight.--I am, etc.,

Institute of Paediatrics,

JERZY ARVAIA

Me jical Academy,

Krakow-

1 Grisham, R. S. C., American fournal of Ophthalmology, 1962, 54. 1119.

Armata, J., Wyszkowski, J., and Krop, J., Polski Tygo.nik Lekarski, 1972, 27, 1895

4 Geils, G. F., Scott, C. W., Baugh, C. M., and Butterworth, C. E., jun., Blood, 1971, 38, 131.

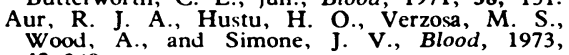
42, 349 .

\section{Diathermy Burn Hazard}

SIR,-I would like to draw attention to a new hazard from the use of the aluminium disposable diathermy plate electrode.

During a recent anterior resection of the rectum an aluminium plate electrode was placed beneath the patient's lumbosacra area. The rectum was washed out with mercuric perchloride solution, a procedure carried out by many colonic surgeons becaus the solution's cytotoxic action on exfoliated malignant cells in the bowel lumen reduces the incidence of anastomotic tumour recurrence.' At the end of the operation the diathermy plate was found to have partly disintegrated and to be covered in white-grey spots. The plate was also very hot and the patient sustained a superficial chemical burn

Inquiries have revealed that a previous chemical burn has been reported when one of these aluminium plates came into contact with the mercuric compound Merthiolate (thiomersal, B.P.), and hospitals were warned of this by the D.H.S.S." Merthiolate is rarely used surgically, but mercuric perchloride is very commonly used for the above mentioned reason, and it would seem that chemical burns are likely to occur unless the aluminium plate is protected from exposure to this substance. The disintegration of the electrode with consequent reduction in conductivity also makes an electrical burn very likely. A non-aluminium plate should be used if exposure to mercuric perchloride might occur.-I am, etc.,

Department of Surgery, Royal Marsden Hospital Goligher, J. C., Surgery of the Anus, Rectum and
Colon, 2nd edn. London, Bailière Tindall and Cassell, 1967.

Hospital Eq $\mathrm{C}$ (ipment Information No. 40. London,
Department of Health and Social Department of Health and Social Security, May
1972 .

\section{Drugs and "Dementia" in the Elderly}

SIR,-In the excellent article by Dr. Tom Arie on "Dementia in the Elderly" (1 December, p. 540) there is a point that has been missed, or perhaps dismissed under the term "drug abuse" towards the end This is that some elderly patients arrive at hospital with a presumptive diagnosis of dementia, often of long standing, which is drug-induced. Dr. Arie's article stressed the untreatability of many causes of dementia; it is a pity that he missed out one of the few that are treatable. My staff are trained to ask the relatives for "the tablets" when the patient comes into hospital. These are set out with a copy of MIMS at the bed-end when I first examine the patient. As many as 10 bottles and boxes may be displayed for one patient. The spectrum over 20 years has changed from barbiturates to tranquillizers and now to hypotensives and antidepressants. Apart from the doubtful wisdom of giving hypotensives to persons over 80 , the forgetfulness which is common in old age leads to erratic dosage and over-dosage. At one time I attributed this dangerous polypharmacy to the "repeat prescription syndrome," but that this is not so is shown by the doctors' letters, which will often state that the patient is at present taking two or even three sedatives, hypotensives, and amitriptyline (itself often an hypotensive drug).

As it is very gratifying to see the "dementia" patient, apathetic on arrival, improve rapidly over the next few days and regain mobility, mental faculties, and control over the bladder merely by stopping all drug treatment, I can only hope that this letter from the lower rungs of the profession will meet the eyes of at least as many as have read the helpful article by Dr. Arie.-I am, etc.,

Derby

BARON RUSSELI

\section{Anaemia in the Elderly}

SIR,-Drs. H. S. Loh and C. W. M. Wilson (8 December, p. 612) criticize my suggestion (3 November, p. 288) that it is reasonable in a primary preventive programme to ensure that the daily diet contains "an adequate amount of protein, 10-12 mg iron, 2-4 $\mu \mathrm{g}$ $\mathrm{B}_{1: .}, 100 \mu \mathrm{g}$ folic acid, $2 \mathrm{mg}$ pyridoxine, and $35 \mathrm{mg}$ vitamin $C$. They believe that a larger quantity of vitamin $C$ is necessary.

It is true that in South Africa, Central America, the Netherlands, Japan, Russia and the U.S.A. the recommended daily intake is higher than in the U.K., but I doubt that this is based on the amount needed for normal haemopoiesis. Indeed, Brise and Hallberg' found that $200 \mathrm{mg}$ or more had to be taken before iron absorption was enhanced, and the highest quantity recommended in these countries is considerably lower-for example, $75 \mathrm{mg}$ in the U.S.A. Moreover, McLennan et al." state: "Neither the mean daily intake of ascorbic acid nor the frequency of a low intake (less than $15 \mathrm{mg}$ / day) differs significantly in relation to the presence of iron deficiency or anaemia." The concept of primary prevention is based on the assumption that the population is healthy. Should anaemia develop in someone whose intake of haemopoietic factors is adequate, then investigation is necessary to elucidate the cause.

I am grateful to Drs. Loh and Wilson for summarizing the actions of vitamin $\mathrm{C}$ on iron metabolism and for supplying a list of references, but I would appreciate it if they produced evidence that a vitamin $C$ intake of $35 \mathrm{mg}$ daily allows iron deficiency to develop in a person whose intake of iron is normal and who has no defect of iron absorption, no increased loss of iron, and no disease interefering with iron metabolism. That, after all, is the crux of the matter.-I am, etc.,

Bridgend General Hospital,

J. H. THOMAS gend, Glam.

1 Brise, H., and Hallberg, L., Acta Medica Scandinavica, 1962, 171, Suppl. No. 376.

McLennan, W. J., Andrews, G. R., MacLeod, C. and Caird, F. I., Quarterly fournal of Medi-

\section{Doctors in South Africa}

SIR,-Dr. G. W. Gale's letter (6 October, p. 51) raises certain points which need comment. Until my departure from South Africa in June I was the secretary of the Medical Committee of the Transvaal Study Circle which managed the Salary Equalization Fund. Over the past four years Black doctors working in Government hospitals in Transvaal have been sending periodic memoranda to the Director of Hospital Services outlining their grievances. These have included salary discrimination, poor promotion prospects in Black hospitals, differences in annual and sick leave, poor accommodation (for example, four Black doctors having to share one room with one telephone when on night duty), no married quarters (for Whites only), no travel allowance (for Whites only) and poor recreation facilities (a swimming pool at Baragwanath Hospital is for Whites only). In July 1972 we were given an interview with the director, Dr. Grové. Needless to say we achieved very little except for a travel grant which all doctors now receive except Africans. As regards senior posts he told us that he would appoint Black doctors in senior posts only if he could set up "nonWhite units" at Black hospitals to be staffed exclusively by "non-Whites." Up to that stage he had met considerable opposition from White doctors and therefore was unable to offer any senior posts. As regards salary discrimination he told us that he could do nothing about it but that he would obtain an interview for us with the Centra Health Service and Co-ordinating Council. He obviously did not keep his promise to us.

It is in this atmosphere of frustration and fear that we, the more privileged Blacks (Asians and Coloureds) decided to upgrade 